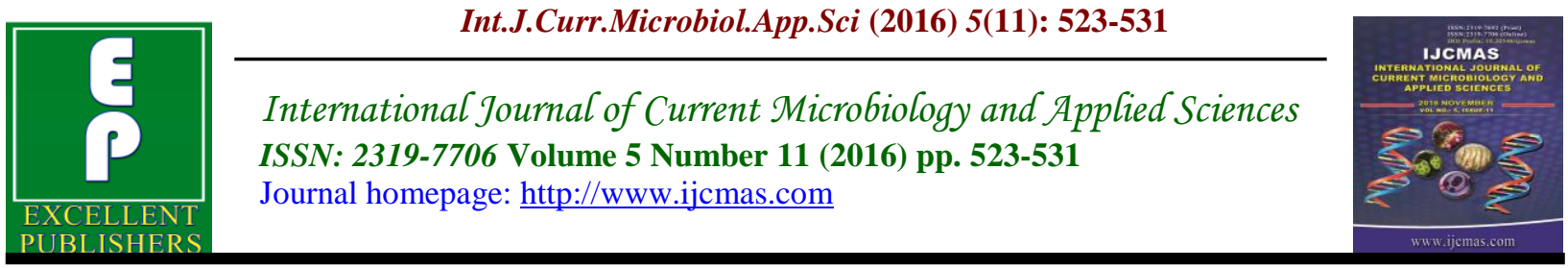

Original Research Article

http://dx.doi.org/10.20546/ijcmas.2016.511.061

\title{
Intestinal Parasitic Infections in Relation to HIV/AIDS Status, Diarrhoea and CD4 T-Cell Count
}

\author{
H.S. Shilpa ${ }^{1}$ and J. Mariraj ${ }^{2}$ \\ ${ }^{1}$ Department of Microbiology, USM-KLE, IMP, Belgaum-590010, Karnataka, India \\ ${ }^{2}$ Department of Microbiology, Vijayanagar Institute of Medical Sciences, \\ Bellary-583104, Karnataka, India \\ *Corresponding author
}

\section{Keywords}

Human

Immunodeficiency

Virus, Diarrhoea,

Opportunistic

infections,

Cryptosporidium

parvum,

CD4 counts.

Article Info

Accepted:

24 October 2016

Available Online:

10 November 2016

\section{A B S T R A C T}

Diarrhoea is a common gastrointestinal symptom in HIV positive patients occurring in more than $90 \%$ of the patients. It is also an independent indicator of mortality in these patients. The present study was conducted with objective to identify the prevalence of intestinal parasitic infections in HIV seropositive patients presenting with diarrhoea and to correlate with CD4 T cell counts. Stool samples from 100 HIV seropositive patients presenting with diarrhoea were collected and subjected to macroscopic examination, micrsoscopic examination and special staining techniques. Samples were also subjected to concentration technique. The CD4 cell counts of the patients were analyse during flow cytometry. (Becton and Dickinson, USA, FACS caliber). Statistical Analysis used: Percentages, Mean, Standard Deviation. Cryptosporidium parvum (66\%) followed by Isospora belli (6\%) was the commonest opportunistic coccidian parasite isolated from patients presenting with chronic diarrhoea, with CD4 counts $<200$ cells $/ \mu$ l. Among non opportunistic parasite E.histolytica (12\%) was the most common. Parasitic infections were seen in $85 \%$ of patients. Coccidian parasites were more common with CD4 counts below $<200$ cells/ $\mu$ l. Among opportunistic parasite cryptosporidium parvum followed by isospora belli was common. E.histolytica was common among non opportunistic parasite. Regular monitoring of CD4 counts and screening for these opportunistic agents in the HIV infected will help clinicians for proper management and in turn helps in reducing the mortality and morbidity associated with infections by these agents.

\section{Introduction}

Infections of gastrointestinal tract are very common in patients with Human Immunodeficiency Virus (HIV) or Acquired immunodeficiency syndrome (AIDS) patients. These infections play a crucial role in HIV pathogenesis, with diarrhoea being the most common clinical presentation. Reports indicate that diarrhoea occurs in 30$60 \%$ of AIDS patients in developed countries and in about $90 \%$ of AIDS patients in developing countries (Kulkarni et al., 2009). Diarrhoea, defined as the passage of 
loose or watery stools atleast three times in $24 \mathrm{hrs}$, is one of the clinical manifestation of HIV infection and usually tends to be chronic (Getachew et al., 2004). In Tropical countries, an episode of chronic diarrhoea that begins acutely and lasts for more than 4 weeks, associated with weight loss, is often the presenting illness of HIV-infected individuals. This diarrhoea wasting syndrome, in association with HIV serology test, is an AIDS defining illness in the World Health Organisation (WHO)'s classification (World Health Organisation, 1986).

The causes of diarrhoea in HIV can be infectious or non infectious. Several studies have shown that infectious diarrhoea in HIV/AIDS is caused by a variety of pathogens including parasites, bacteria, viruses, and fungi. There is no specific combination of intestinal pathogens in HIVassociated diarrhea and the etiological agents vary from patient to patient and from country to country depending on the geographical distribution, endemicity, seasonal variation of the enteric pathogens, and also on the immune status of the patients. Noninfectious diarrhoea could be due to ART related adverse effects and HIV enteropathy (Arun et al., 2012).

The presence of opportunistic parasites Cryptosporidium parvum, Cyclospora cayetanensis, Isospora belli and Microsporidia are documented in patients with AIDS. Non opportunistic parasites such as Entamoeba histolytica, Giardia lamblia, Trichuris trichiura, Ascaris lumbricoides, Strongyloides stercoralis and Ancylostoma duodenale are frequently encountered in developing countries but are not currently considered opportunistic in AIDS patients.

C. parvum, I. belli and E.histolytica have been reported as the most frequently identified organisms in HIV infected individuals with diarrhoea from India and other parts of the world (Sangamesh et al., 2012).

The present study was undertaken to identify the most prevalent enteric parasites causing diarrhea in HIV infected patients and their association with immune status (CD4 count) in a tertiary care hospital in India.

\section{Materials and Methods}

\section{Study population}

This was a prospective hospital based study conducted over a period of one year from January 2013- December 2013on confirmed HIV seropositive patients, who satisfied the inclusion criteria. The inclusion criteria were: 1). serologically confirmed HIV infected adult and paediatric patients. 2) patients with history of diarrhoea, which was defined as loose stool occurring more than three times a day. Patients who had received anti-parasitic treatment for diarrhoea in past 3 weeks were excluded.

\section{Specimen Collection, Transport and Storage}

Stool specimens were collected according to the WHO standard procedure. Three consecutive stool samples were collected in sterile leak proof plastic containers with a wide mouth and a tight-fitting lid. The stool samples collected were divided into two parts. One part was mixed with $10 \%$ buffered formalin saline in the ratio of three parts of formalin to one part of the sample and the second part was the plain stool sample.

The stool samples were fixed in $10 \%$ formalin saline, concentrated using formyl acetone and examined through direct observation (in saline, $0.85 \% \mathrm{NaCl}$ solution, Lugol's iodine) for the detection of ova, 
larva, trophozoites and cysts of intestinal parasites. Smears of direct and concentrated specimens were examined by modified Ziehl -Neelsen acid fast staining, Trichrome staining, Iron and hematoxyline staining.

\section{Collection of CD4 counts data}

$3 \mathrm{ml}$ of venous blood was collected from HIV seropositive patients in a vacutainer containing $\mathrm{k} 3$ EDTA and cd4 counts data was obtained by automated flow cytometry analyzer FACS caliber (beckton dickinson) at ART PLUS centre.

\section{Results and Discussion}

A total of 100 samples from HIV positive patients presenting with diarrhea were collected . Maximum patients were of age group 21-40(54\%), who were sexually active, with mean age 36.3 years. The study group included $65(65 \%)$ male population and $35(35 \%)$ female population,with a male: female ratio of 1.85:1. Heterosexual (93\%) contact was the commonest mode of acquisition of HIV infection followed by perinatal $(5 \%)$ transmission. None of the patients gave a history of homosexuality or intravenous drug abuse. Stool samples from HIV patients were collected and screened for the presence of parasites. Most of the stool samples were watery (75\%)followed by semi-formed (19\%)and mucus and blood stained $(6 \%)$. The macroscopic examination revealed that positivity of finding a pathogen in sample was four times more in case of watery samples compared to semi formed samples.

\section{Parasites Detected}

Out of 100 patients, parasites were detected in 85 samples. Enteric parasites identified in the stool samples included opportunistic and non opportunistic pathogens. opportunistic parasites were found in 67(78.8\%) and non- opportunistic parasites were seen in 18 $(21.2 \%)$ samples. The parasites isolated were C.parvum (66\%), I.belli (6\%), C.cyatenensis (1\%), E.Histolytica (12\%), G.lamblia (10\%), Taenia spp (2\%) H.nana (1\%). (Table.1)

\section{Mixed Infections}

Out of 100, 12 patients with chronic diarrhea had mixed infections. 6 of these patients had mixed opportunistic infections and 6 had both opportunistic and non opportunistic infections (Table.2).

Mixed coccidian infections was seen in patients with chronic diarrhoea with CD4 counts $<200$ cells $/ \mu 1.16$ patients with $\mathrm{CD} 4$ counts $<200$ cells $/ \mu 1$ had opportunistic infections (100\%). Among 43 patients with CD4 counts >200-499 cells/ $\mu 1,35$ had opportunistic infections $(81 \%)$ and 8 had non opportunistic infections.16 patients with CD4 counts $>500$ cells $/ \mu 1$ had opportunistic infections $(61 \%)$ ).Non opportunistic infections were not seen below $<200$ cells/ $\mu 1$ The chi-square statistic is 9.1227. The P-Value is 0.010448 . The result is significant at $\mathrm{p}<0.05$. (Graph.1)

\section{Correlation between Parasites Detected and Diarrhoea}

In present study 65 patients presented with acute diarrhoea, total of $50(76 \%)$ patients had parasitic infections and in 15 patients no parasites were detected. 35 patients had chronic diarrhoea, all of them had parasitic infection (100\%).(Table.3)

\section{Correlation between Opportunistic Parasites, Cd4 Counts and Diarrhoea}

The overall prevalence of Cryptosporidium was $66 \%$ with $11 \%$ patients having chronic diarrhoea with CD4 counts $<200$ cells $/ \mu 1$. 
The result is significant at $\mathrm{P}<0.05$.Isospora (6\%) and Cyclospora (1\%) were isolated from patients with CD4 counts $<200$ cells $/ \mu 1$. The distribution of parasites in each cd4 category along with the type of diarrhea is shown in table 3. Isospora and Cyclospora were significantly found in chronic diarrhea with cd4 counts $<200$ cells/ $\mu 1$ (Table.4)

In present study the overall prevalence of enteric parasites was $85 \%$.Our study showed similar results done by Abebe Alemu et al., and Kurniawan et al., (2009). Different factors contribute to the prevalence of intestinal parasites among a given population, the most important ones being environmental, parasitic and host factors like living conditions, exposure to pets and animals, source of water, type of toilet used, and personal hygiene practice and also the endemicity of parasite in particular geographical area (Cheesebrough, 1999). The high prevalence of protozoa parasitism, compared to that of helminth infections was noted. The drug mass administration with albendazole could explain the low rate of helminthic infections.

\section{Opportunistic and Non Opportunistic Parasites}

Among the enteric parasites which were detected, 67(78.8\%) were opportunistic and $18(21.2 \%)$ were non opportunistic parasites. Study conducted by Nityavyas et al., (2013) showed $68.7 \%$ and $31.03 \%$ opportunistic and non opportunistic infection. In the present study, the overall prevalence of non opportunistic parasites were detected in $21.2 \%$ HIV positive patients with diarrhea. Study conducted by S.B.Lucas and Tawanda Gumbo et al., (1990, 1999) have reported prevalence of non opportunistic parasites varied from 5$30 \%$ in HIV infected patients.
Study conducted in India by Venkatesh Naik et al., (2012) showed around $22.56 \%$ of non opportunistic infections in HIV patients presenting with diarrhoea. The importance of tropical non opportunistic intestinal parasitic infections should not be neglected. Thus highlighting the need for early detection and treatment of such infections to reduce the morbidity in HIV positive patients with diarrhoea.

\section{Correlation between Parasites Detected and Diarrhoea}

In present study 65 patients presented with acute diarrhoea, total of $50(76 \%)$ patients had parasitic infections and in 15 patients no parasites were detected. 35 patients had chronic diarrhoea, all of them had parasitic infection $(100 \%)$.

The results correlate with study done by Nityavyas et al., and Lanjewar et al., although our results showed higher percentage of positive samples

The higher parasitic isolation in chronic diarrhoea (100\%) compared to acute diarrhea $(76 \%)$ cases was because majority of parasites isolated in the present study were coccidian group which are more frequently encountered in chronic diarrhoea cases except cryptosporidium which was found with equal frequency in both type of diarrhoea.

\section{Mixed Infections}

In our study we found 6 cases of dual infections which is comparable with study conducted by Sucilathangam et al., (2011). Mixed parasite infection is common in areas where various types of parasites coexist with favourable behavioural and ecological patterns of transmission. Increased rate of mixed infections among HIV positive 
individuals, particularly in those with CD4 counts below 200 cells $/ \mu \mathrm{L}$ may be because of higher prevalence of certain parasites among the risk group, which favors the frequent mixing up.Health effects of polyparasitism depends on the types of parasite co-infection, mixed intestinal helminths and protozoa cause persistent diarrhoea and anaemia.

Coinfection with helminths in HIV leads to chronic immune activation leading to hyporesposiveness and anergy resulting in increase in plasma HIV viral load thus accelerating progression to AIDS. Hence screening of helminths must be included in routine parasitic examination. The higher rate of dual infection in HIV patients in the risk group, which facilitates their mixing up (Shah et al., 2003).

In general, such prevalence of these nonopportunistic parasites in the present study could have been the effect of water and food contamination, or it could have been due to poor personal hygiene. Chronic infection with helminthes explains some of the elements of chronic immune activation that may also be found in HIV infection. This type of immune activation has been suggested as a major factor for the increased susceptibility and progression of HIV infection Occurrence of these parasites was significantly associated with low CD4 counts $(<200$ cells/ul $)$ These infections therefore should not be overlooked in HIVinfected patients especially those with low CD4 counts and presenting with diarrhoea.

\section{Correlation between Opportunistic Parasites, CD4 Counts and Diarrhoea}

The overall prevalence of Cryptosporidium was $66 \%$ with $11 \%$ of patients having chronic diarrhoea with CD4 counts $<200$ cells $/ \mu 1$. The prevalence of cryptosporidial diarrhoea in HIV infected individuals in different parts of India has ranged from 0.7 $87 \%$ in symptomatic individuals and from $1.4-57 \%$ in asymptomatic individuals (Ajjampur et al., 2008).

Table.1 Parasites detected in HIV seropositive patients

\begin{tabular}{|l|l|l|}
\hline & Opportunistic & Non opportunistic \\
\hline Protozoa & Cryptosporidium & E.histolytica \\
\hline & Isospora & Giardia lamblia \\
\hline & Cyclospora & \\
\hline Helminths & & Taenia \\
\hline & & H.nana \\
\hline
\end{tabular}

Table.2 Mixed Infections

\begin{tabular}{|l|l|}
\hline Parasites detected & No of patients \\
\hline Cryptosporidium\&isospora & 5 \\
\hline Cryptosporidium\&cyclospora & 1 \\
\hline $\begin{array}{l}\text { Cryptosporidium \& } \\
\text { E.histolytica }\end{array}$ & 2 \\
\hline Cryptosporidium \& Giardia & 1 \\
\hline $\begin{array}{l}\text { Cryptosporidium, Giardia \& } \\
\text { Teania }\end{array}$ & 1 \\
\hline Giardia \& E.histolytica & 1 \\
\hline Giardia \& H.nana & 1 \\
\hline
\end{tabular}


Table.3 Correlation between parasites detected and diarrhea

\begin{tabular}{|l|l|l|l|}
\hline \multicolumn{2}{|l|}{ Acute diarrhoea(n-65) } & Chronic diarrhoea(n-35) \\
\hline Parasite present & Parasite absent & Parasite present & Parasite absent \\
\hline 50 & 15 & 35 & 0 \\
\hline
\end{tabular}

Table.4 Correlation between opportunistic parasites, CD4 counts and Diarrhoea

\begin{tabular}{|l|l|l|l|l|}
\hline Parasite & Diarrhoea & $<200$ cells/ $\mu \mathrm{l}$ & $\begin{array}{l}>200-499 \\
\text { cells } / \mu 1\end{array}$ & $>500$ cells/ $\mu 1$ \\
\hline Cryptosporidium & acute & 4 & 18 & 12 \\
\cline { 2 - 5 } & chronic & 11 & 17 & 4 \\
\hline Isospora & chronic & 6 & - & - \\
\hline Cyclospora & chronic & 1 & - & - \\
\hline
\end{tabular}

Fig.1 Oocyst of Cryptosporidium, Isospora and Cyclospora on Modified Z N Stain
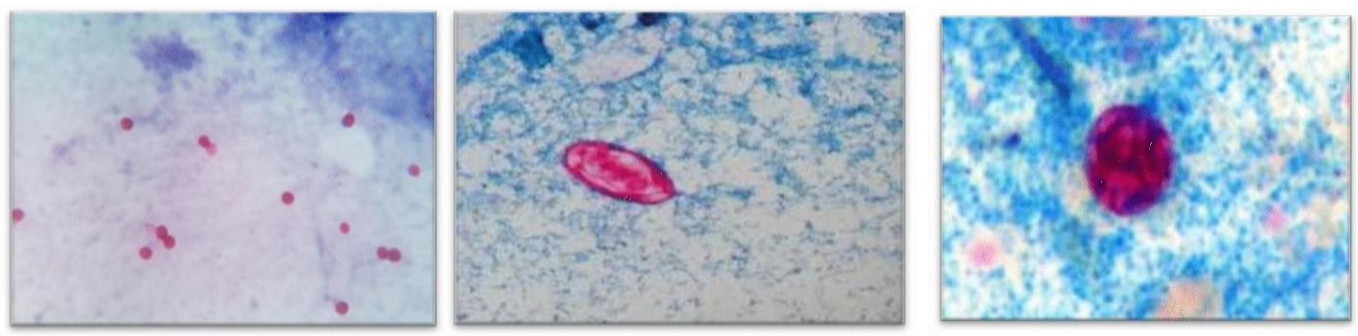

Graph.1 Opportunistic Vs Non opportunistic Infections

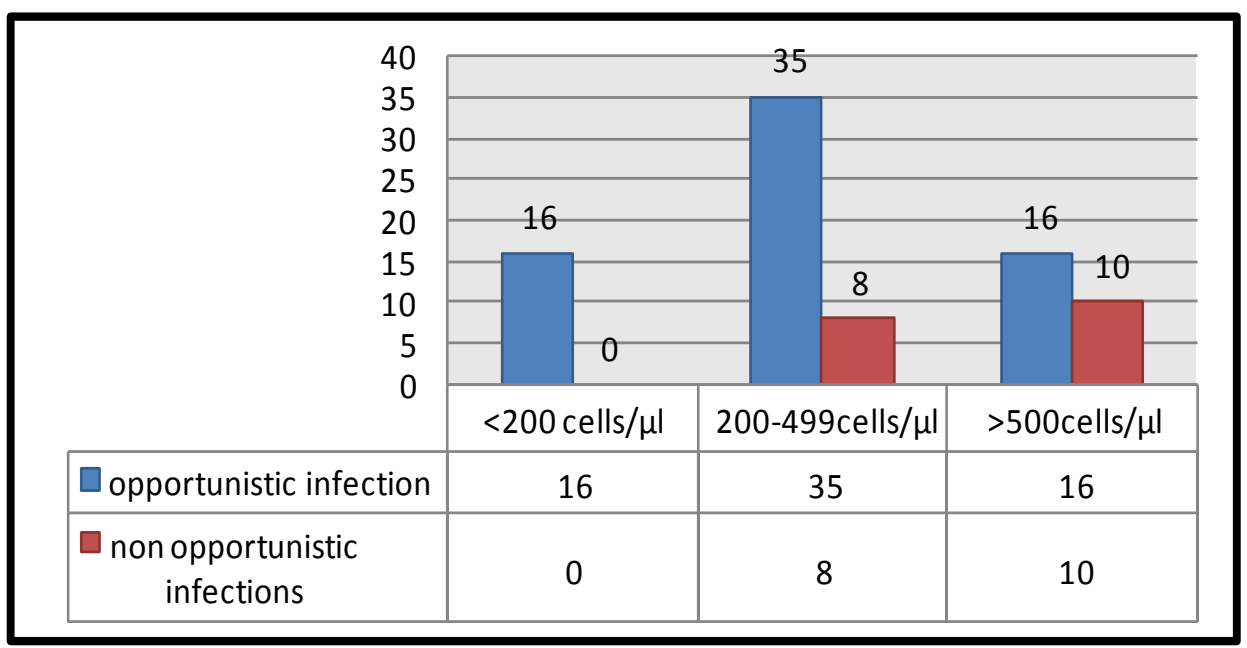

The lifetime risk of infection by Cryptosporidium in HIV patient is $10 \% .{ }^{21}$ Poor personal hygiene, low socioeconomic status and contaminated drinking water may be responsible for the high frequency of Cryptosporidium. Therefore it is suggested that simple steps like drinking safe water, maintaining high level of environmental and personal hygiene and avoiding contact with contaminated soil 
should be taken to prevent the occurrence of these diseases in AIDS patients. The prevalence of Isospora in present study was 6\%.Isospoara belli is more common in tropical and subtropical than in temperate climates. Isospora belli is the cause of gastrointestinal infections in about 1\%-3\% of patients with AIDS and diarrhoea in USA, but in $15 \%-19 \%$ of AIDS patients in developing countries.

Cyclospora (1\%) was isolated from patients presenting with chronic diarrhoea with CD4 counts $<200$ cells $/ \mu 1$. Study conducted by Sucilathangam et al., showed similar results. The highest prevalence of parasites depends on the endemicity of a particular enteric parasite in the community which determines the incidence and prevalence of particular parasitic infections in HIV/AIDS

In conclusion, Cryptosporidium was found to be the most common parasite in HIV positive patients presenting with diarrhoea followed by Isospora. Among non opportunistic infection E. histolytica (12\%) was noted. Coinfections with helminths was also noted. Detection of Cryptosporidium parvum, Isospora belli, cyclospora significantly below the CD4 T-cell count of $<200$ cells/ul indicates typical opportunistic nature of these parasites.

An early diagnosis and treatment would greatly help in improving the quality of life and prevent further deterioration of the immune system. All chronic diarrhoea cases need to be investigated for coccidian infections and screened for HIV infection de novo as majority of the coccidian parasites are associated with chronic diarrhoea with diarrhoea being the presenting symptom of HIV in many cases. Simple techniques such as Modified acid fast staining can be used to screen stool samples of all HIV positive patients with diarrhoea even in resource limited settings.
Early diagnosis of opportunistic and non opportunistic parasitic infections and prompt treatment definitely contribute to increased life expectancy of infected individuals by delaying the progression to AIDS.

Etiology of diarrhoea could not be determined in $15 \%$ of the patients, suggesting a need for comprehensive etiological studies covering bacterial, viral, parasitic causes of diarrhoea among HIV infected patients in India.

\section{Acknowledgment}

To all our colleagues both teaching and nonteaching.

\section{References}

Abebe Alemu, Yitayal Shiferaw, GebetawGetnet, AgregawYalew, Zelalem Addis. 2011. Opportunistic and other intestinal parasites among HIV/AIDS patients attending gambit higher clinic in Bahir Dar city, North west Ethiopia. Asian Pacific J. Tropical Med., 661-665.

Ajjampur, S.S., Sankaran, P., Kang, G. 2008. Cryptosporidium Species in HIV- infected individuals in India: An Overview. The National Med. J. India, 21(4): $178-184$

Amatya, R., Shreatha, R., Poudyal, N., Bhandari, S. 2011. Opportunistic Intestinal Parasites and CD4 Count in HIV Infected People. J. Pathol. Nepal, 1: $118-121$

Arun, K., Jha, Uppal, B., Sanjim, C., Preena, B., Roumi, G., Prabhav, A., and Richa, D. 2012. Clinical and Microbiological Profile of HIV/AIDS Cases withdiarrhea in North India. $J$. Pathogens, 1-7.

Cheesebrough, M. 1995. District laboratory practice in tropical countries $2^{\text {nd }}$ 
edition Cambridge: butterworth and Co Cambridge university press 5: 208. GadiBorkow and ZviBentwich. 2004. Chronic Immune Activation Associated With Chronic Helminthic and Human Immunodeficiency Virus Infection: Role Of Hyporesposivness and Anergy. Clin. Microbiol. Rev., 1 7(4): 1012-1030.

Getachew Haliemariam, Afework Kassu, Gemeda Abede, Ebba Abate, Demekech Damte, Endris Mekonnen, Fusao Ota. 2004. Intestinal Parasitic Infections in HIV/AIDS and HIV Seronegative individuals in a Teaching Hospital, Ethopia. Jpn. J. Infect. Dis., 7: 41-43.

Goodgame, R.W. 1996. Understanding intestinal spore forming protozoa:Cryptosporidia

Microsporidia, Isospora and Cyclospora.Ann Intern Med., 124: 429-41

Kulkarni, S.V., Kairon, R., Sane, S.S., Padmawar, P.S., Kale, V.A., Thakar, M.R., Mehendale, S.M. and Risbud, A.R. 2009. Opportunistic Parasitic Infections in HIV/AIDS Patients Presenting with Diarrhoea by the level of Immunosuppression. Indian J. Med. Res., 130: 63-66.

Kurniawana, T., Karyadib, S.W. Dwintasaria, I.P. Saria, E. Yunihastutib, S. Djauzib, H.V. Smith. 2009. Intestinal Parasitic Infections in HIV/AIDS Presenting With Diarrhoea in Jakarta Indonesia. Transactions of the Royal Society of Tropical Medicine and Hygiene, 103:892-898.

Lanjewar, D.N., Rodrigues, C., Saple, D.G., Hira, S.K., Dupont, H.L. 1996. Crypyosporidium,Isospora and Strongyloides in AIDS.The National Med. J. India, 9(1),1996.

Luca, Sb. 1990. Missing Infections In Aids
.Transactions Of The Royal Society Of Tropical Med. Hygiene, 84(1): 34-38.

Lucas, S.B. 1990. Missing infections in AIDS. Trans R. Soc. Trop. Med. Hyg., 86: 353-4.

Manoj, J., Chowdhary, A.S., Dalal, P.J., Maniar, J.K. 2002. Parasitic Diarrhoea In Patients With Aids.The National Med. J. India, 15(2): 72-74.

Sangamesh, M., Malaji, Gopal Bajaj, S.A. Kora, Satish Biradar, Renuprasad Chikkamath. 2012. Study Of Opportunistic Parasitic Infections at Various Level Of Immunosuppression In HIV/AIDS Patients Presenting With Dirrhoea. J. Pharmaceytical and Biomedical Sci., 20(20): 1-3.

Shah, U.V., Purohit, B.C., Chandralekha, D., Mapara, M.H. Coinfection With Cryptosporidium, Isospora and S.Stercoralis in a Patient with AIDS. Indian J. Medical Microbiol., 21(2): 137-138.

Sucilathangam, G., Velvizhi, Palaniappan, Anna, T. 2011. The Prevalence Of Coccidian Parasites in and around Tirunelvelii in HIV Positive Individuals and its Correlation with the CD4Count. J. Clin. Diag. Res., 5(6): 1182-1186.

Tawanda Gumbo, Steedman Sarbah, Innocent T. Gangaidzo, Ynes Ortega, Charles R. Sterling, Angela Carville, Saul Tzipori And Peter M. Wiest. 1999. Intestinal Parasites in Patients With Diarrhea and HIV Infections in Zimbabwe. AIDS, 13:819-821.

Venkatesh, N.R., Ravichandraprakash, H., Ukey, P.M., Vijayanath, V., Shreeharsha, G., Vinay Kumar Chandak. 2012. Opportunistic intestinal parasitic infections in HIV/AIDS patients presenting with diarrhoea and their correlation with CD4 + T lymphocytecounts. Int. J. Pharmacy and Biol. Sci., 2(4): 239- 
299.

Vyas, N., Pathan, N., Aziz, A. 2012. Enteric Pathogens In HIV Positive Patients With Diarrhoea and their Correlation with CD4+T-Lymphocyte Counts. Tropical Parasitol., 2: 29-34.

Vyas, N., Smita, Babita, S., Munesh, K. 2013. The Prevalence of Intestinal Parasitic infestation and the Related
Profile of the CD4 Counts in HIV/AIDS People With Diarrhoea in Jaipur City. J. Clin. Diagnostic And Res., (3): 454-456.

World Health Organisation. 1986. Provisional WHO clinical case definition for AIDS. Wkly. Epidemiol. Rec., 10: 303-306.

\section{How to cite this article:}

Shilpa, H.S., and Mariraj, J. 2016. Intestinal Parasitic Infections in Relation to HIV/AIDS Status, Diarrhoea and CD4 T-Cell Count. Int.J.Curr.Microbiol.App.Sci. 5(11): 523-531. doi: http://dx.doi.org/10.20546/ijcmas.2016.511.061 